\section{Morphological Variability of Snowdrops in the Central Part of the Balkan Peninsula}

\author{
Filip Jovanović ${ }^{1}$, Dragica Obratov-Petković, and Ivana Bjedov \\ Department of Landscape Architecture and Horticulture, Faculty of \\ Forestry, University of Belgrade, 1 Kneza Višeslava, Belgrade 11000, Serbia
}

Ivana Živanović, Sonja Braunović, and Tatjana Ćirković-Mitrović Institute of Forestry, 3 Kneza Višeslava, Belgrade 11000, Serbia

\section{Gordana Tomović}

Institute of Botany and Botanical Garden “Jevremovac, ” Faculty of Biology, University of Belgrade, 43 Takovska, Belgrade 11000, Serbia

Additional index words. Galanthus, Southeastern Europe, numerical taxonomy, multivariate analysis, plant selection, horticulture

\begin{abstract}
To address the issues of taxonomic delimitation and to select the material with desirable traits for horticultural use, a comprehensive study of the total variability of morphological characters of two naturally occurring snowdrop species (Galanthus nivalis L. and Galanthus elwesii Hook.) in the central part of the Balkan Peninsula was conducted. The analyses were performed for 16 quantitative characters of aboveground parts of 630 plants collected at 21 geographical points in the territory of the Republic of Serbia. To identify the trends in morphological differentiation, descriptive, univariate and multivariate statistical procedures were employed. Most of the examined characters exhibited moderate degrees of variability ( $\mathrm{CV}$ from $10 \%$ to $20 \%$ ) and the values of several characters exceeded the limits of variation stated in literature. Samples were mostly morphometrically homogeneous, with comparatively high similarity; only four populations of $G$. nivalis from the southern and southeastern part of the country were discrete. It is questionable whether these populations merit formal taxonomic recognition at any infraspecific level, but given their decorative qualities, the selected plants can be introduced into cultivation as horticultural plants.
\end{abstract}

Species of the genus Galanthus L. (Amaryllidaceae), known as snowdrops, rank among the finest garden plants and are particularly welcomed as early flowering harbingers of spring. The genus comprises 21 species of bulbous, petaloid monocotyledons, native to Europe, Asia Minor, and the Near East, with centers of diversity found in Greece and regions adjacent to the Balkans, Turkey, and the Caucasus (Davis, 1999, 2001; Tan et al., 2014). Snowdrops are the world's most traded wild-sourced bulb genus. As a result of illegal collection, habitat destruction, and climate change they are threatened in the wild and several species of the genus are listed on the International Union for Conservation of Nature (IUCN) Red List of Threatened Species. However, since 1990, all species have been listed in Appendix II of the Convention on International

Received for publication 11 Apr. 2018. Accepted for publication 19 June 2018.

The work was supported by the Ministry of Education, Science and Technological Development (Grants 43007, 173030, and 31070). We are also grateful to Marko Dragojlović, Aleksandar Vlainić, Slavko Jovanović, Bojan Zlatković, Nikola Jovanović, and Aleksandar Živanović for their assistance during the field research.

${ }^{1}$ Corresponding author. E-mail: filip.a.jovanovic@ gmail.com.
Trade in Endangered Species of Wild Fauna and Flora, and the trade in wild specimens has been heavily restricted (IUCN, 2018).

Snowdrops are easy to recognize thanks to the nearly universal presence of two leaves and solitary pendant white flowers composed of six perianth segments, which are arranged in two whorls with the inner ones being smaller than the outer and with green markings. However, the species delimitation is problematic and the infrageneric classification uncertain, which causes problems in the implementation of trade and conservation policies (Rønsted et al., 2013). Snowdrops are difficult to distinguish and classify because of the lack of clearly definable morphological characters and the presence of great variability (Davis and Barnett, 1997). Delimitation of species has been mainly based on leaf characteristics (color, width, and vernation), flowering time, the number of green marks on the inner perianth segments, and distribution (Zonneveld et al., 2003). Numerous studies have been conducted in the past few decades to find taxonomically informative data, including morphological (Budnikov, 2011; Sidjimova, 2006), anatomical (Davis and Barnett, 1997), and molecular investigations (Rønsted et al., 2013; Zonneveld et al., 2003).
Along with taxonomic research, many regional accounts have been published (Bavcon, 2008; Brickell, 1984; Delipavlov, 1971; Maly, 1904; Pospichal, 1897; Scopoli, 1772; Webb, 1980; Wulfen, 1858; Zeybek and Sauer, 1995) but the genus has remained insufficiently investigated in the central part of the Balkan Peninsula. Chorology and ecology of snowdrops in Serbia have recently undergone a detailed study (Jovanović et al., 2016), indicating that the genus is represented by two species. The species $G$. nivalis has a broad distribution, whereas $G$. elwesii is distributed mainly in the eastern part of the country. The latter is distinguished from the former by its wider and glaucous leaves, supervolute vernation and the presence of a basal mark on the inner perianth segments (Jovanović et al., 2016). Before this study, the genus was mentioned by several authors (Petković et al., 1982; Stjepanović-Veseličić, 1975); however, due to the different approaches and difficulties in the classification of the genus, the actual patterns of its diversity and distribution have remained uncertain. Many varieties and forms of $G$. nivalis have been recorded in Serbia (Radić, 2000), although no infraspecific taxa are currently recognized for this species (Davis, 1999, 2001). In addition, there are ambiguous data that suggest the presence of Galanthus gracilis Čelak. in the flora of Serbia (Adamović, 1909; Jovanović et al., 2012). Thus, a study on the delimitation of the taxa occurring in the country has become necessary.

The study of different types of variability has considerable theoretical and practical importance, for example, to clarify the problems of systematic characters and to select the material with desirable traits for practical use. Genetics and ecological adaptability can also be confirmed by morphologically variable characteristics (Lavadinović and Marković, 2012). In this study, morphometric analysis of 17 populations of G. nivalis and four populations of $G$. elwesii from Serbia was performed to assess phenotypical differences among them. The study should show the nature of their variability and whether the values of the examined characters are discreet or there is a continuous variability between the samples. In particular, the aims of the study were to clarify the patterns of morphological variations and disclose the level of morphological differentiation within the analyzed species and to indicate the most informative characters for the identification of possible infraspecific taxa. Furthermore, the article gives a proposal for the introduction of new breeding material into cultivation.

\section{Materials and Methods}

The observation and collection of plant material were conducted in 21 geographical points of the Republic of Serbia (Table 1), during the growing seasons of 2012, 2013, and 2014. To avoid the influences of specific habitats and microclimate, the collected plant material was transported to the Faculty of Forestry, University of Belgrade (lat. 
$44.782750^{\circ} \mathrm{N}$, long. $20.425453^{\circ} \mathrm{E}$ ), planted in plastic pots and placed outdoors in raised beds. The material was identified using the taxonomic keys proposed by Davis $(1999,2001)$ and the amended key created for Galanthus in Serbia (Jovanović et al., 2016). Voucher specimens were deposited in the Herbarium of the Institute of Botany and Botanical Garden "Jevremovac," BEOU (Thiers, 2018).

The morphometric study was carried out on living material in 2015, at the peak of the flowering period. Exactly 30 specimens were taken from each sampled population, following the randomization principle, and studied with 16 morphometric characters (Table 2). Additional characteristics, such as leaf color, vernation, marks on the inner perianth segments, and flowering time, were observed. All measurements were taken with accuracy of $0.01 \mathrm{~mm}$.

The obtained numerical data were processed using descriptive, univariate, and multivariate statistical methods. Raw data were used to calculate mean values $(\overline{\mathrm{X}})$ of all characters and to determine average $\pm \mathrm{SD}$ and CV for every mean (Table 2; Supplemental Table 1). Comparison and determination of the essentiality of the difference between the means was carried out using the analysis of variance (ANOVA). The observed morphological characters were studied by comparing the minimum, maximum, and mean values of different samples with literature records. Before performing the principal component analysis (PCA), canonical discriminant analysis (CDA) and a cluster analysis (CA), the morphometric characters were tested for the normality and collinearity. After testing several data transformation procedures, the characters departed from the normality were subjected to Box-Cox transformation (Box and Cox, 1964). PCA was conducted to show the overall morphological variation and relationships between individuals from all populations. CDA was performed to

Table 1. Galanthus nivalis (N) and Galanthus elwesii (E) samples used for analysis.

\begin{tabular}{|c|c|c|c|}
\hline Sample & Collection site & Coordinates & Voucher \\
\hline $\mathrm{N} 1$ & Mt. Cemernica, Maskovo & lat. $43.502089^{\circ} \mathrm{N}$, long. $20.036717^{\circ} \mathrm{E}$ & BEOU16779 \\
\hline $\mathrm{N} 2$ & Mt. Ozren, Jermencic & lat. $43.619272^{\circ} \mathrm{N}$, long. $21.834086^{\circ} \mathrm{E}$ & BEOU16781 \\
\hline N3 & Mt. Tara, Mitrovac & lat. $43.932111^{\circ} \mathrm{N}$, long. $19.448511^{\circ} \mathrm{E}$ & BEOU16782 \\
\hline N4 & Pcinja gorge, St. Prohor Pcinjski & lat. $42.326583^{\circ} \mathrm{N}$, long. $21.897494^{\circ} \mathrm{E}$ & BEOU16783 \\
\hline N5 & Mt. Zlatibor, Caldov Vijadukt & lat. $43.723130^{\circ} \mathrm{N}$, long. $19.688680^{\circ} \mathrm{E}$ & BEOU16784 \\
\hline N6 & Mt. Kopaonik, Jelak & lat. $43.311740^{\circ} \mathrm{N}$, long. $20.856320^{\circ} \mathrm{E}$ & BEOU16785 \\
\hline N7 & Mt. Fruska Gora, Norcev & lat. $45.158272^{\circ} \mathrm{N}$, long. $19.863319^{\circ} \mathrm{E}$ & BEOU16786 \\
\hline N8 & Mt. Goc, Trivunacki Potok & lat. $43.553800^{\circ} \mathrm{N}$, long. $20.775242^{\circ} \mathrm{E}$ & BEOU16788 \\
\hline N9 & Mt. Jastrebac, Prokop & lat. $43.420681^{\circ} \mathrm{N}$, long. $21.380947^{\circ} \mathrm{E}$ & BEOU16790 \\
\hline N10 & Mt. Belava, Debeli Del & lat. $43.202075^{\circ} \mathrm{N}$, long. $22.455447^{\circ} \mathrm{E}$ & BEOU16791 \\
\hline N11 & Vrsac Mts., Djakov Vrh & lat. $45.129775^{\circ} \mathrm{N}$, long. $21.347092^{\circ} \mathrm{E}$ & BEOU16792 \\
\hline N12 & Niska Banja, Banjsko Brdo & lat. $43.289153^{\circ} \mathrm{N}$, long. $22.009783^{\circ} \mathrm{E}$ & 16793 \\
\hline N13 & Obedska Bara, Plandiste & lat. $44.707370^{\circ} \mathrm{N}$, long. $20.026640^{\circ} \mathrm{E}$ & BEOU16796 \\
\hline N14 & Mt. Kosmaj, near the monument & lat. $44.470060^{\circ} \mathrm{N}$, long. $20.572710^{\circ} \mathrm{E}$ & BEOU16798 \\
\hline N15 & Mt. Radan, Gajtan & lat. $43.002406^{\circ} \mathrm{N}$, long. $21.477114^{\circ} \mathrm{E}$ & BEOU16799 \\
\hline N16 & Bor: Mt. Stol, at the top & lat. $44.177050^{\circ} \mathrm{N}$, long. $22.135344^{\circ} \mathrm{E}$ & BEOU16800 \\
\hline N17 & Mt. Suva Planina, Malo Konjsko & lat. $43.163681^{\circ} \mathrm{N}$, long. $22.255658^{\circ} \mathrm{E}$ & BEOU16882 \\
\hline E1 & Svrljig Mts., Ples & lat. $43.351675^{\circ} \mathrm{N}$, long. $22.165172^{\circ} \mathrm{E}$ & 6801 \\
\hline E2 & Pirot: Crni Vrh, near the & lat. $43.182544^{\circ} \mathrm{N}$, long. $22.652589^{\circ} \mathrm{E}$ & BEOU16802 \\
\hline E3 & Mt. Vidlic, Basarski Kamen & lat. $43.177319^{\circ} \mathrm{N}$, long. $22.684847^{\circ} \mathrm{E}$ & BEOU16803 \\
\hline E4 & Sicevo gorge, Kusaca & lat. $43.323167^{\circ} \mathrm{N}$, long. $22.079094^{\circ} \mathrm{E}$ & BEOU16637 \\
\hline
\end{tabular}

check the hypothesis that the analyzed sample was composed of discrete groups morphologically differentiated one from another. Overall differences between the compared groups were defined by Euclidean distances used in the clustering analysis according to the unweighted pair group method with arithmetic mean (Sneath and Sokal, 1973). All statistical analyses were performed with Statistica (1997; StatSoft, Inc., Tulsa, OK).

\section{Results and Discussion}

Based on the measurements of 16 morphological characters of 17 samples of $G$. nivalis (N1-17) and four samples of $G$. elwesii (E1-4), an overview was made covering the total variability of these species on the territory of Serbia (Table 2; Supplemental Table 1). In comparison with literature data (Supplemental Table 2), the minimum values of sheet diameter in almost all analyzed samples (except N17) and the mean values in about half of the samples were smaller than the minimum size stated for the feature (5 mm) (Davis, 1999, 2001). The maximum value of sheet diameter in N17 exceeded the upper limit given in the literature $(8 \mathrm{~mm})$ (Davis, 2001). Leaves were green (N1, N3, $\mathrm{N} 5, \mathrm{~N} 8$, and N11) to glaucous (N10, N16; E1-4) and variable in vernation (E1-4). The smallest mean values of leaf width (N2, N4, and N12) were close to the lower limit recorded in the literature $(2 \mathrm{~mm})$ (Zahariadi, 1966), and the samples represented a distinct homogeneous group based on the statistical difference detected between the means. Two of these samples (N4 and N12) had other conspicuous characteristics, such as glaucous central stripe on the leaves and early flowering. All samples of G. elwesii had unusually narrow leaves and the values fitted well into the data range of leaf widths given for closely related species G. gracilis [from (2)3 to $12(23) \mathrm{mm}$ ] (Davis, 2001). The maximum values of

Table 2. Descriptive statistics $(N=$ number of measured cases, $\overline{\mathrm{X}}=$ mean, $\mathrm{MIN}=$ minimum value, $\mathrm{MAX}=$ maximum value, $\mathrm{sD}, \mathrm{CV})$, factor loadings of principal component analysis (PCA1 and PCA2), and discriminant loadings of canonical discriminant analysis (CDA1 and CDA2) related to morphometric characters of Galanthus nivalis and Galanthus elwesii (all measures in $\mathrm{mm}$ ).

\begin{tabular}{|c|c|c|c|c|c|c|c|c|c|c|c|c|c|c|c|c|c|c|}
\hline & \multirow[b]{2}{*}{$\mathrm{N}$} & \multicolumn{4}{|c|}{ G. nivalis } & \multirow[b]{2}{*}{$\mathrm{CV}$} & \multirow[b]{2}{*}{$\mathrm{N}$} & \multicolumn{4}{|c|}{ G. elwesii } & \multirow[b]{2}{*}{$\mathrm{CV}$} & \multicolumn{2}{|c|}{ PCA } & \multicolumn{2}{|c|}{$\mathrm{CDA}$} & \multicolumn{2}{|c|}{ ANOVA } \\
\hline & & $\overline{\mathrm{X}}$ & MIN & MAX & SD & & & $\overline{\mathrm{X}}$ & MIN & MAX & $\mathrm{SD}$ & & PCA1 & PCA2 & CDA1 & CDA2 & $\mathrm{F}$ & $P$ \\
\hline Percentage & & & & & & & & & & & & & 52.27 & 13.94 & 42.79 & 17.74 & & \\
\hline Leaf length & 510 & 160.26 & 59.97 & 246.26 & 38.58 & 24.07 & 120 & 160.34 & 65.40 & 245.04 & 37.98 & 23.69 & $-^{2}$ & - & - & - & 38.05 & 0.0000 \\
\hline Leaf width & 510 & 7.76 & 4.84 & 11.24 & 1.24 & 16.04 & 120 & 10.91 & 8.40 & 13.85 & 1.24 & 11.33 & $\mathbf{0 . 7 0 ^ { y }}$ & -0.42 & 1.04 & 0.70 & 91.49 & 0.0000 \\
\hline & 510 & 168.17 & 58.24 & 275.35 & 32.95 & 19.59 & 120 & 154.48 & 84.17 & 216.63 & 24.33 & & - & - & - & - & 23.65 & 0.0000 \\
\hline $\mathrm{Sp}$ & 510 & 34.25 & 20.95 & 50.97 & 5.28 & 15.40 & 120 & 35.50 & 25.27 & 46.30 & 4.15 & 11.68 & 0.75 & 0.31 & -0.33 & -0.21 & 16.77 & 0.0000 \\
\hline anth segments & 510 & 19.94 & 12.90 & 28.02 & 2.85 & 14.28 & 120 & 19.91 & 14.50 & 25.09 & 2.45 & 12.31 & 0.74 & 0.54 & -3.02 & 2.43 & 15.95 & 0.0000 \\
\hline W & 510 & 8.39 & 3.45 & 13.20 & 1.70 & 20 & 120 & 10.56 & 6.71 & 14.08 & 88 & 17.76 & 0.88 & -0.18 & 0.88 & 0.20 & 33.67 & 0.0000 \\
\hline & 510 & 9.71 & 6.60 & 13.03 & 3 & & 1 & 11.35 & 8.50 & 13.70 & 2 & 1 & 0.85 & -0.10 & 2.49 & -2.81 & 30.47 & 0.0000 \\
\hline Widt & 510 & 6.72 & 3.43 & 10.06 & 1.03 & 15.29 & 120 & 7.03 & 4.48 & 9.22 & 1.04 & 14.81 & 0.80 & 0.25 & -0.64 & 0.25 & 22.59 & 0.0000 \\
\hline $\begin{array}{l}\text { Ratio of lengths of outer to } \\
\text { inner p. s. }\end{array}$ & 510 & 2.05 & 1.57 & 2.53 & 0.15 & 7.47 & 120 & 1.75 & 1.44 & 2.19 & 0.14 & 7.87 & $-0,03$ & 0.89 & 1.09 & -1.32 & 49.36 & 0.0000 \\
\hline $\begin{array}{l}\text { Ratio of widths of outer to } \\
\text { inner p. s. }\end{array}$ & 510 & 1.25 & 0.60 & 1.77 & 0.17 & 13.39 & 120 & 1.50 & 1.12 & 1.86 & 0.14 & 9.50 & 0.49 & -0.52 & -0.16 & -0.17 & 41.18 & 0.0000 \\
\hline
\end{tabular}

${ }^{\mathrm{z}}$ Multivariate analysis not performed.

${ }^{\mathrm{y}}$ Boldfaced values denote variables with loadings $>0.7$ for PCA and CDA, and $P<0.05$ for analysis of variance (ANOVA). 
spathe length in all samples of $G$. elwesii exceeded the maximum size stated in the literature not only for the species, but also for the genus (40 mm) (Davis, 2001). No literature data were found on the spathe width of G. elwesii, but according to Davis (1999, 2001) and Flora Vascular (2018), it should not exceed $5 \mathrm{~mm}$ in the genus and $3.1 \mathrm{~mm}$ in G. nivalis. In our study, all maximum values and almost all mean values in both studied species (except in E4) exceeded these limits. This could be explained by the fact our data were obtained by measuring widely opened spathes, whereas those given in literature might have been determined at the spathe's natural position or from herbarium specimens. The minimum values of pedicel length in most of the samples of $G$. nivalis (except N4, N6, N7, N12, and N14) were smaller than that recorded in the literature $(12 \mathrm{~mm})$ (Davis, 1999, 2001). All minimum values of pedicel length in G. elwesii were smaller than that stated for $G$. elwesii $(14 \mathrm{~mm})$ (Davis, 2001) and even for generally smaller G. gracilis $(10 \mathrm{~mm})$ (Davis, 2001). The same applies to the mean values (except in E4) compared with the data given for $G$. elwesii and the mean value in E1 compared with the data given for G. gracilis. However, it must be pointed out that our data refer to the part of pedicel emerging from the spathe, whereas literature data probably refer to the pedicel as a whole. The mean values of the length of outer perianth segments in $G$. elwesii were close to the lower limit given in the literature (15 mm) (Webb, 1980) and the minimum value in $\mathrm{E} 2$ exceeded the limit. The minimum value of the width of outer segments in E4 exceeded the lower limit given in the literature $(7 \mathrm{~mm})$ (Zeybek and Sauer, 1995), whereas the mean value was close to the same limit. Inner perianth segments occasionally had flared apices (one specimen in N16; E1-4) and variable marks. The maximum values of the width of the inner perianth segments in G. elwesii exceeded the literature records $(8 \mathrm{~mm})$ (Brickell, 1984; Davis, 2001), whereas the mean values were close to the limit. In some populations (N17; E1-3), the maximum values of stamen length were larger than those stated in the literature for G. nivalis $(8.6 \mathrm{~mm})$ (Flora Vascular, 2018) and G. elwesii (8 mm) (Delipavlov, 1971). The mean values of ovary diameter in almost all samples of G. elwesii (except E3) were close to that recorded in $G$. gracilis (4 mm) (Stern, 1956), whereas the minimum value was close to that stated for the genus (2 mm) (Davis, 1999). The minimum values of style length in almost all samples of $G$. nivalis (except N6, N8, N10, and N17) were smaller than that given for the species (7.1 $\mathrm{mm}$ ) (Flora Vascular, 2018), and in nine samples (N1-3, N7, N9, N11-13, and N15) they were smaller than that given for the genus (6.6 mm) (Davis, 2001). The maximum values of style length in seven samples of $G$. nivalis (N2, N4, N6, N8, N10, N16, and N17) were larger than that recorded in the literature (9 mm) (Stern, 1956), whereas the maximum values in all samples of G. elwesii, as well as the average values in E1 and E2, exceeded the maximum size given not only for the species, but also for the genus (9 mm) (Davis, 2001). Finally, the style in snowdrops should be longer than the stamens (Brickell, 1984) but in N15 it is shorter.
In the ANOVA, most of the characters in both studied species exhibited moderate degrees of variability among populations (CV from $10 \%$ to $20 \%$ ) (Table 2), confirming Budnikov (2011) and Sidjimova (2006). Within the group of highly variable characters,
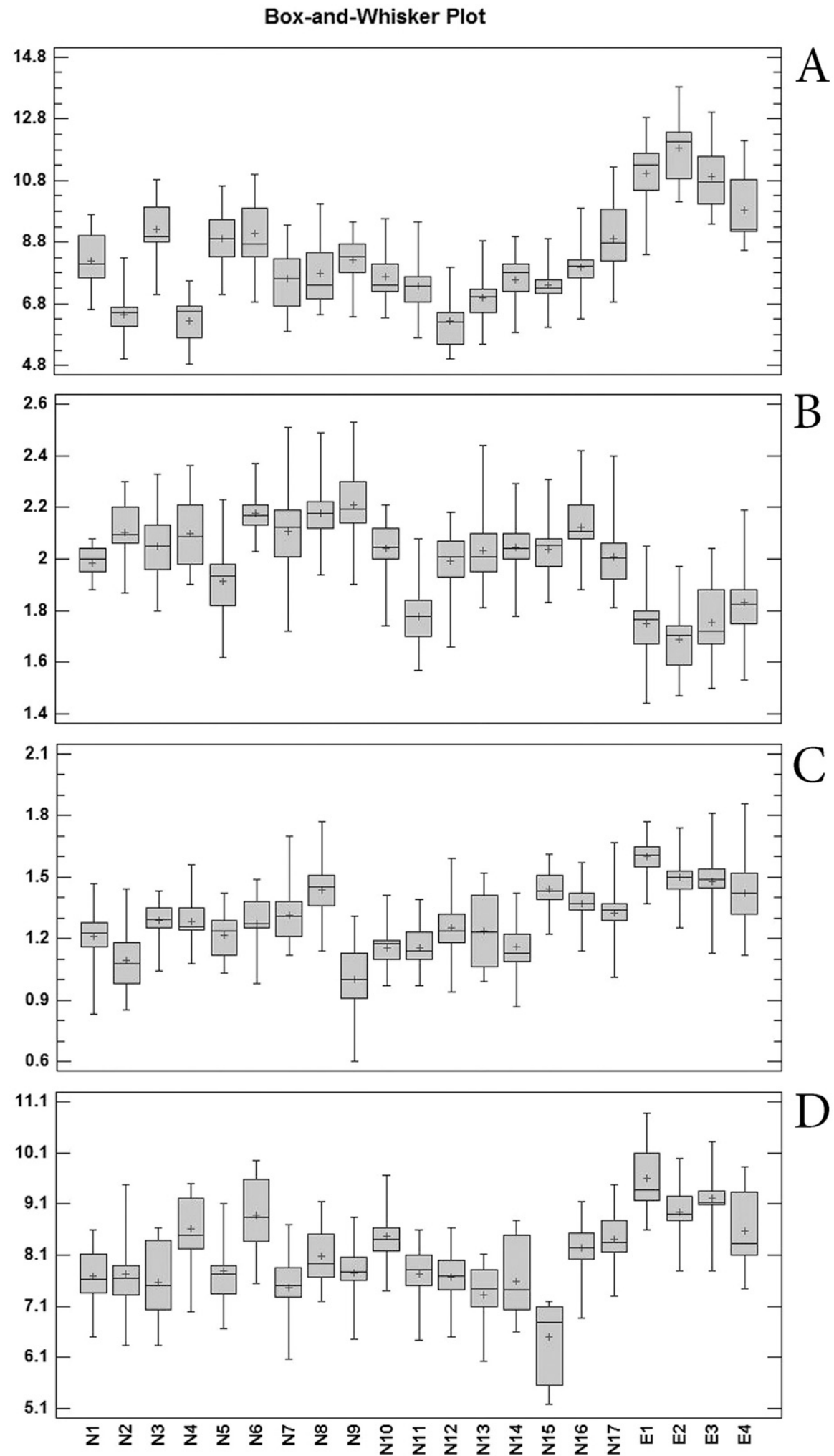

Fig. 1. Box and whisker plots of basic parameters of characters with the highest $F$ ratios: (A) leaf width, (B) ratio of lengths of outer to inner perianth segments, $(\mathbf{C})$ ratio of widths of outer to inner perianth segments, (D) style length. Middle sign $=$ mean, middle line $=$ median, box $=$ mean, and standard deviation, whisker $=$ variation range $($ all measures in $\mathrm{mm})$. 
CV were significantly higher than $20 \%$, and they were as follows: pedicel length up to $39.73 \%$, leaf length up to $30.88 \%$, and scape height up to $24.61 \%$. The lowest $\mathrm{CV}$ were found for the ratio of lengths of outer to inner perianth segments (from $3.04 \%$ to $11.96 \%$ ), stamen length (from $4.46 \%$ to $7.98 \%$ ), style length (from $5.31 \%$ to $11.26 \%$ ), and the length of inner perianth segments (from $7.15 \%$ to $12.73 \%$ ) (Supplemental Table 1). However, in contrast to these results, some other features of some populations of $G$. nivalis from western Ukraine (leaf width, spathe length, width of outer perianth segments, and ovary diameter) were also highly variable (Budnikov, 2011) and the most variable feature of $G$. elwesii in Bulgaria was the width of leaves (CV from $15.3 \%$ to $28.9 \%$ ) (Sidjimova, 2006). In addition, Korkut (1994) found great variability of all the measured characters of $G$. elwesii, except for the length of inner perianth segments.

Analysis of variance revealed significant differences in all of the characters examined and significant contribution of all of the characters to the differentiation of populations (Table 2). The characters that contributed to the minimum extent, although still significant, were the following: length of outer perianth segments, spathe length, and stamens length. By contrast, leaf width, ratios of lengths and widths of outer to inner perianth segments, as well as style length, highly contributed to the differentiation of populations, as shown in Fig. 1A-D. Regarding other characters, different populations contributed in varying degrees to the general differentiation. For most characters analyzed, populations E1, E2, N9, N13, and N15 contributed the most to differentiation.

Given the high variability of leaf length, pedicel length, and scape height, multivariate statistical procedures were carried out using the remaining 13 morphometric characters. Similar to the results of Korkut (1994), eight characters (sheet diameter, leaf width, spathe width, length and width of outer perianth segments, length of inner perianth segments, ratio of lengths of outer to inner perianth segments, and ovary diameter) departed from the normality and they were transformed.

The first two principal components, with eigenvalues $>1$, explained $66.21 \%$ of the total variation. Most of the variation was explained by the first axis $(52.27 \%)$ and $13.94 \%$ by the second one. Several characters, with factor loadings $>0.70$, influenced the first axis (length and width of outer perianth segments, length and width of inner perianth segments, spathe length and width, ovary diameter, style length, and leaf width), whereas the second axis was influenced by the ratio of lengths of outer to inner perianth segments (Table 2). Being much less pronounced than the variation of size (the first axis), the variation of shape (the second axis) resulted in the separation of populations along the second axis. Corresponding to the two studied species, two groups of populations are formed, as shown in Fig. 2A. Populations of $G$. nivalis formed a group mainly at the positive part of the second axis, whereas the populations of $G$. elwesii are separated as a group at the negative part of the same axis. There is a certain overlap between these two groups, including populations N15 and E4 and individuals from N3 and N17. No clear differentiation within these two groups is visible, only a trend of separation of N9 from the rest of populations of $G$. nivalis along the second axis. Dispersive distribution of individuals, originating from different populations of $G$. elwesii, indicates that the variation within these populations is at a similar level or greater than the variation between the populations.

In the CDA, the first function accounted for $42.79 \%$ of the discrimination and the second one discriminated another $17.74 \%$. Four characters, with factor loadings $>0.70$, are responsible for the differentiation along both axes (leaf width, lengths of outer and inner perianth segments, and ratio of lengths of outer to inner perianth segments). One additional character (width of outer perianth

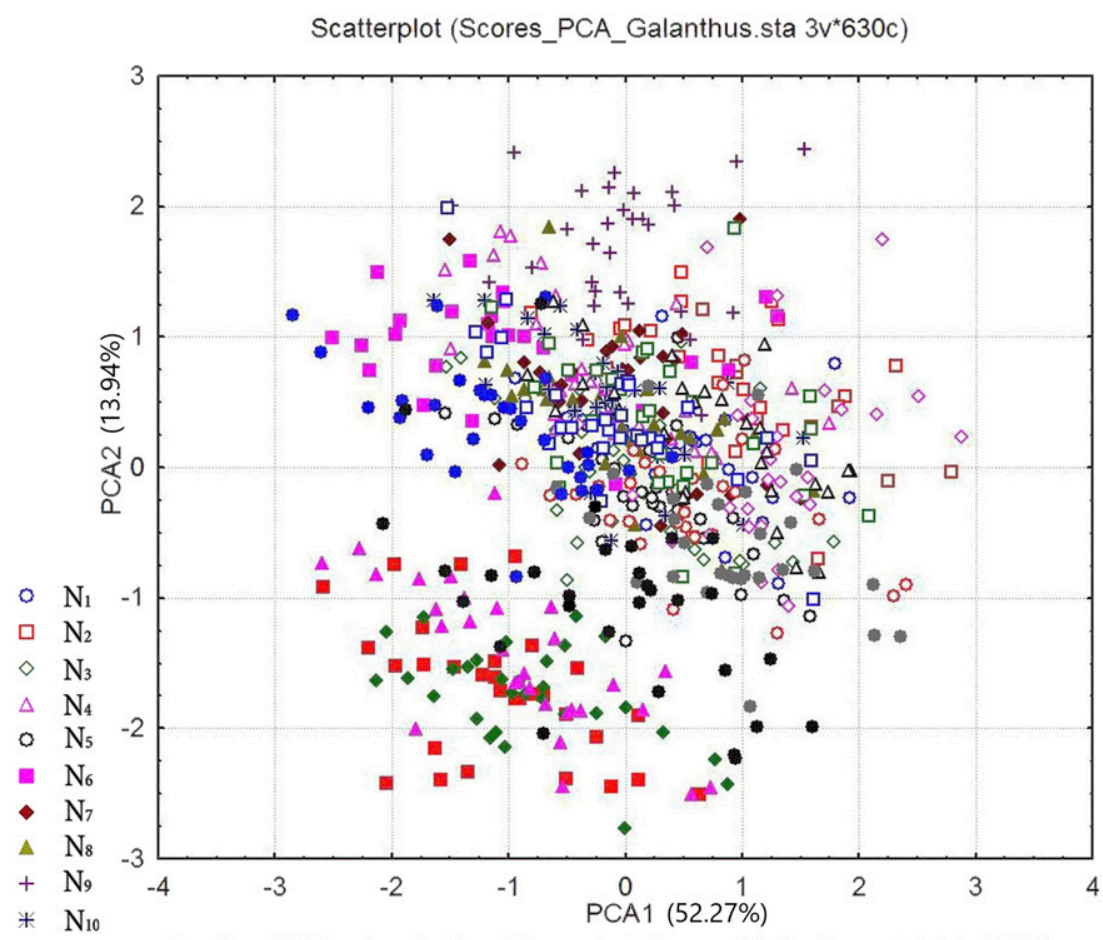

A

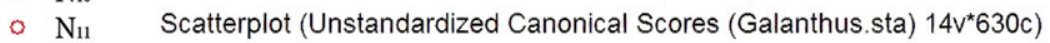

$\square \mathrm{N}$
$\diamond \mathrm{N}$
$\Delta \mathrm{N}$
$\square \mathrm{N}$
$-\mathrm{N}$
$-\mathrm{E}$
$-\mathrm{E}$
$-\mathrm{B}$

$\mathrm{N}_{12}$
$\mathrm{~N}_{13}$
$\mathrm{~N}_{14}$
$\mathrm{~N}_{15}$
$\mathrm{~N}_{16}$
$\mathrm{~N}_{17}$
$\mathrm{E}_{1}$
$\mathrm{E}_{2}$
$\mathrm{E}_{3}$
$\mathrm{E}_{4}$

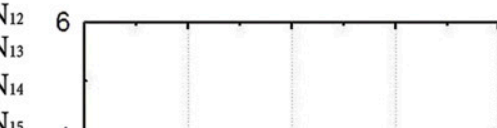

$N_{15} 4$

$\mathrm{N}_{16}$

$\mathrm{E}_{4} \stackrel{\circ}{\stackrel{\circ}{+}}$

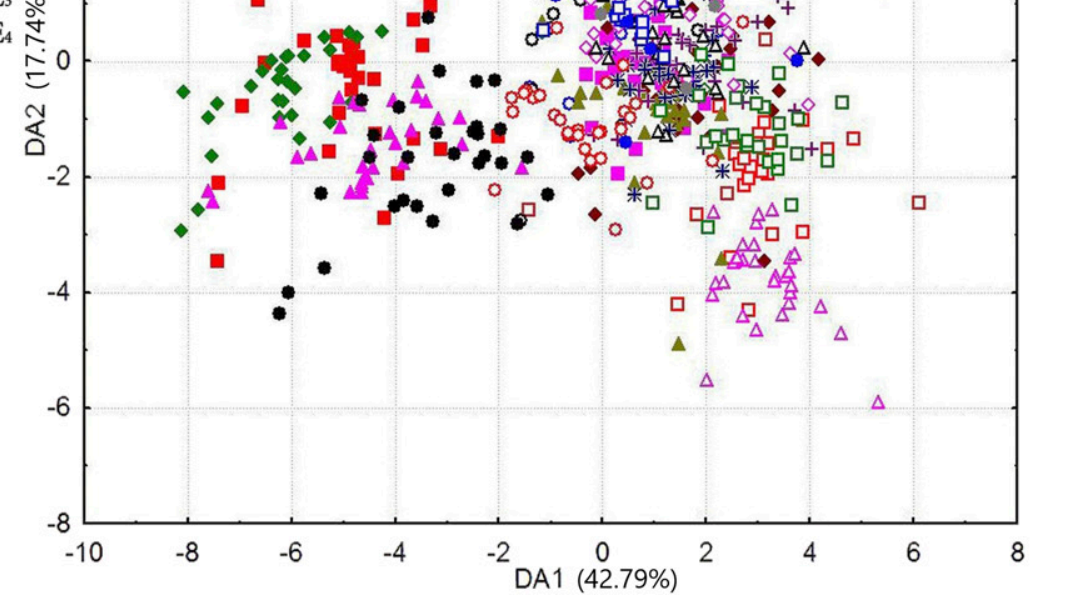

Fig. 2. (A) Principal component analysis (PCA) and (B) canonical discriminant analysis scatterplots of 17 samples of Galanthus nivalis (N1-17) and four samples of Galanthus elwesii (E1-4) based on 13 morphometric characters. 
segments) influenced the first axis and two additional characters (stamen length and style length) influenced the second one (Table 2). CDA resulted in two morphologically differentiated entities, along the first axis, as shown in Fig. 2B. Similar to the results of PCA, populations of $G$. nivalis formed one group, whereas populations of $G$. elwesii formed the other group. There is a certain overlap between these two groups, including samples N11 and E4 and individpopulations of $G$. nivalis, population N4 is separated from the other at the positive part of the second axis and there is a trend of separation of N2 and N12 along the same discriminant axis. On the other hand, there is no clear differentiation between the samples of $G$. elwesii. Classificatory discriminant analysis showed that the percentage of correctly classified individuals from the studied populations is not less than $73 \%$, except in N14 $(60 \%)$. In addition, in more than half of the populations, this percentage is more than $80 \%(\mathrm{~N} 7, \mathrm{~N} 10, \mathrm{~N} 11$, and N13; E1-4) and $90 \%$ (N4, N12, N15, and N16) (Supplemental Table 3$)$.

In the CA, the samples are differentiated into two main clusters, as shown in Fig. 3. The first cluster consists of populations of $G$. nivalis and the second cluster is formed of populations of $G$. elwesii, similar to the results of PCA and CDA. Within the first main cluster, there are three groups, suggesting that significant phenotypic differences exist among these groups of samples. The first group includes 13 samples from northern, western, central, and eastern Serbia (N1, uals from N2 and E3. Within the group of

N3, N5-11, N13, N14, N16, and N17), which are morphometrically homogeneous, with comparatively high similarity. Three populations, originating from southeastern Serbia (N2, N4, and N12) formed the second group. The third group, containing only N15, is formed at the greatest linkage distance within the first cluster. In the cluster of G. elwesii, all samples have a great similarity and small linkage distances from the overall similarity line.

The multivariate morphometric analysis (CDA) and, particularly, the CA show that the analyzed populations are morphometrically differentiated into several distinct groups (subclusters). According to the classificatory analysis, the percentages of correctly classified individuals within these groups are 97\%, 94\%, 97\%, and 98\%, respectively. The first group combines populations originating from various sites of the country, whereas the second, the third, and the fourth groups bring together geographically neighboring populations. Grouped in the second subcluster, populations of $G$. nivalis from southeastern Serbia, specifically Pcinja gorge (N4), Mt. Ozren (N2), and Niska Banja (N12) are distinguishable from the others by their narrow leaves, which often possess a conspicuous stripe of wax running along the central vein. Similar populations from the southern half of the Central Balkans have been recorded in the literature (Davis, 1999, 2001) but referring to Croatia and Montenegro. The population from Mt. Radan (N15), representing the third subcluster, is easily recognizable by its styles that are shorter than the stamens. Because the study

Tree Diagram for 21 Cases Unweighted pair-group average Euclidean distances

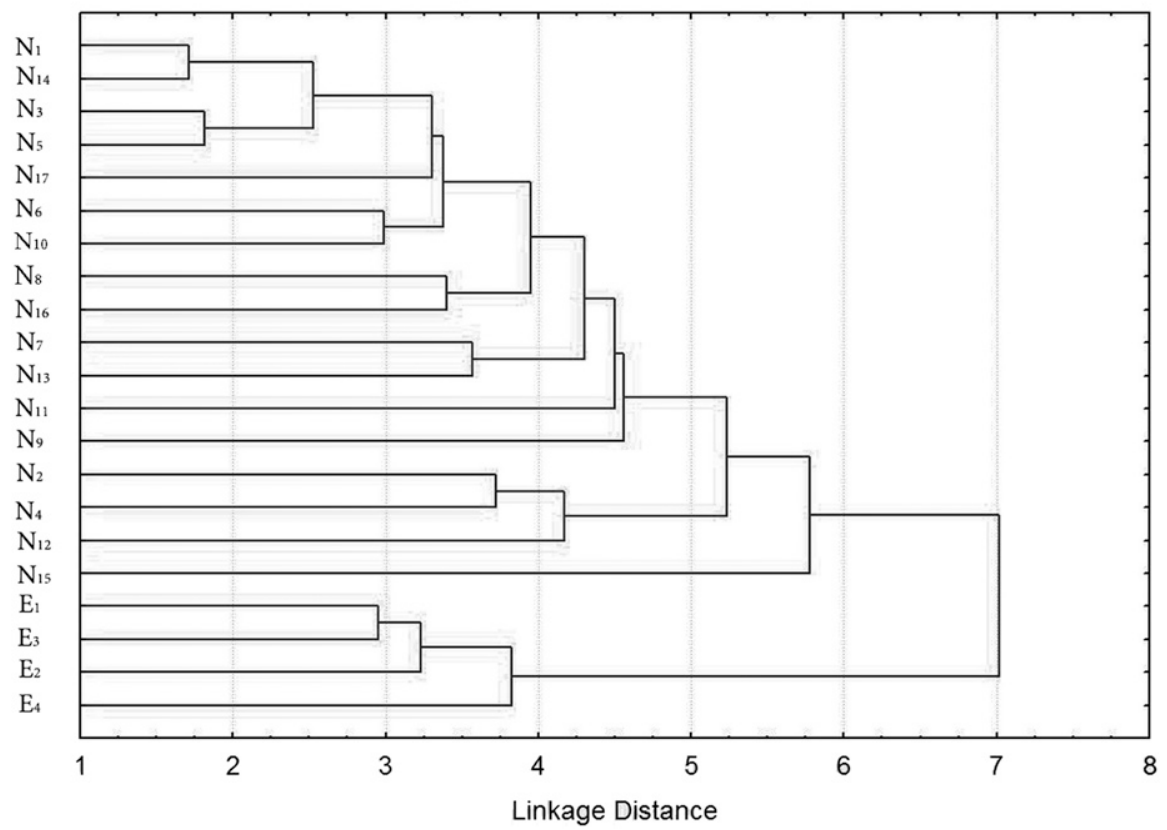

Fig. 3. Unweighted pair group method with arithmetic mean dendrogram of relationships of 17 samples of Galanthus nivalis (N1-17) and four samples of Galanthus elwesii (E1-4) based on 13 morphometric characters. was conducted in experimental conditions, the observed differentiation could be caused by genetic or evolutionary factors and it would not be surprising if cryptic taxa exist within what is presently known as $G$. nivalis. Cryptic species G. samothracicus Tan \& Biel (resembling G. nivalis) have recently been described in Greece (Tan et al., 2014), confirming the opinion that the phenomenon of cryptic speciation is an important factor in assessing the species diversity on the Balkan Peninsula. However, in conformity with the opinion of Davis (1999), regional variants of $G$. nivalis should not be recognized in a formal taxonomic manner because that would cause instability in already complex and difficult classification of the genus. Variability of $G$. nivalis is considered attributable to its wide distribution (Davis, 1999, 2001). Although it is possible that some infraspecific taxa will need to be recognized after further research (Davis, 2001), a comprehensive molecular and phylogenetic study is required.

On the other hand, $G$. elwesii is often confused with G. gracilis (Adamović, 1909; Jovanović et al., 2012). They have the same type of marks on the inner perianth segments and the same leaf coloration. The key distinguishing character is vernation, which is applanate in $G$. gracilis and supervolute in $G$. elwesii. In addition, the apex of the inner perianth segments is usually flared in $G$. gracilis, whereas in G. elwesii it is more or less straight (Davis, 1999, 2001). In our study, leaf width and vernation, apex of inner perianth segments, and ovary diameter of the samples of $G$. elwesii corresponded both to $G$. elwesii and G. gracilis. Similar findings have been reported by Sidjimova (2006), including the width of leaves, width of outer perianth segments, and length and width of inner perianth segments. However, the CA showed comparatively high similarity between the samples. Moreover, according to Rønsted et al. (2013), narrow leaves, variable vernation, and smaller plant size are common traits of Balkan G. elwesii compared with its Turkish representatives. Therefore, we do not consider G. gracilis to be present in Serbia. In fact, G. elwesii occurring in the Balkans may represent a distinct taxon or even a separate species (Rønsted et al., 2013), and its taxonomical status need to be revised in keeping with the results of future investigations.

The results of the study contribute to the general knowledge of the morphological variability of snowdrops in the central part of the Balkan Peninsula. Regardless of the matter of formal taxonomic recognition, variants possessing desirable traits can be introduced into cultivation as horticultural plants. Snowdrops have been known in horticulture of the western countries for a long time but in Serbia we still fail to use them widely; they are almost exclusively grown in private gardens. In our opinion, populations of $G$. nivalis from southeastern Serbia, especially Pcinja gorge (N4) and Niska Banja (N12) and all samples of G. elwesii have high decorative qualities, representing an excellent starting material for cultivation and breeding 
new cultivated taxa for decoration of both gardens and parks. The results will also be valuable for the management and protection of the wild snowdrop taxa occurring in Serbia.

\section{Literature Cited}

Adamović, L. 1909. Die vegetationsverhältnisse der Balkanländer (Mösische länder) umfassend Serbien, Altserbien, Bulgarien, Ostrumelien, Nordthrakien und Nordmazedonien, p. 1-567. In: A. Engler and O. Drude (eds.). Vegetation der Erde. Vol. XI. W. Engelmann, Leipzig, Deutschland (in German).

Artjushenko, Z.T. 1970. Amarillisovie (Amaryllidaceae Jaume St.-Hilaize) SSSR - Morfologia, sistematika i ispolzovanie. Akademia nauk SSSR Moskva, Botanicheskii Institut VL, SSSR, Komarova, Leningrad (in Russian).

Bavcon, J. 2008. Common snowdrop (Galanthus nivalis L.) and its diversity in Slovenia. Botanical Garden, Department of Biology, Biotechnical Faculty, University of Ljubljana, Ljubljana, Slovenia.

Box, G.P.E. and D.R. Cox. 1964. An analysis of transformations. J. R. Stat. Soc. [Ser A] 26(2): 211-252.

Brickell, C.D. 1984. Galanthus, p. 365-372. In: P.H. Davis, R.R. Mill, and K. Tan (eds.). Flora of Turkey and the east Aegean Islands. Vol. VIII. Univ. Press, Edinburg, Scotland.

Budnikov, G. 2011. Morphological variation of specimens and populations of Galanthus nivalis L. in western regions of Ukraine. Thaiszia 21:95-109.

Davis, A.P. 1999. The genus Galanthus. Timber Press, Portland, OR.

Davis, A.P. 2001. The genus Galanthus: Snowdrops in the wild, p. 9-64. In: M. Bishop, A.P. Davis, and J. Grimshaw (eds.). Snowdrops: A monograph of cultivated Galanthus. The Griffin Press, Maidenhead, UK.

Davis, A.P. and J.R. Barnett. 1997. The leaf anatomy of the genus Galanthus L. (Amaryllidaceae J. St.-Hil.). Bot. J. Linn. Soc. 123(4): 265-362.
Delipavlov, D. 1971. Rod't Galanthus L. (kokiche) v Bulgaria. Izvestiya Bot. Inst. 21:161-167 (in Bulgarian).

Flora vascular. 2018. Galanthus nivalis L. 9 Feb. 2018. <https://www.floravascular.com/index.php? $\mathrm{spp}=$ Galanthus $\% 20$ nivalis/ $>$.

IUCN. 2018. The IUCN red list of threatened species. Version 2017-3. 25 May 2018. <www. iucnredlist.org/>.

Jovanović, F., D. Obratov-Petković, M. Niketić, and S. Vukojičić. 2016. Distribution of the genus Galanthus L. (Amaryllidaceae) in Serbia. Bot. Serb. 40(1):69-81.

Jovanović, F., D. Obratov-Petković, and B. Zlatković. 2012 Vrsta Galanthus gracilis Čelak. (Amaryllidaceae) u flori Srbije. Bul. For. 106:101-112. (in Serbian).

Korkut, A. 1994. Research on variabilities in some important characters of Galanthus elwesii Hook. var. elwesii grow [sic] under natural conditions. Acta Hort. 355:189-194.

Lavadinović, V. and N. Marković. 2012. The differences of needle length of Douglas-fir provenances at two sites in test plantations. Sustain. For. 65/66:7-14.

Maly, K. 1904. Beiträge zur kenntnis der Flora Bosniens und der Herzegowina. Verh. Zool.Bot. Ver. Wien 54:165-309 (in German).

Petković, B., B. Tatić, and V. Veljković. 1982. Rod Galanthus L. (Amaryllidaceae) u SR Srbiji. Biosistematika 8:111-116 (in Serbian).

Pospichal, E. 1897. Flora des Österreichischen Küstenlandes. Vol. 1. Franz Deuticke, Leipzig, Wien, Österreichisch-Ungarische Monarchie (in German).

Radić, J. 2000. Infraspecijska varijabilnost vrste Galanthus nivalis L. 1753 na Fruškoj gori. Institut za Biologiju, Prirodno-matematički fakultet, Univerzitet u Novom Sadu, Novi Sad, Srbija, BSc Thesis (in Serbian).

Rønsted, N., D. Zubov, S. Bruun-Lund, and A.P. Davis. 2013. Snowdrops falling slowly into place: An improved phylogeny for Galanthus (Amaryllidaceae). Mol. Phylogenet. Evol. 69:205-217.

Scopoli, J.A. 1772. Flora Carniolica. Impensis Ioannis Pavli Kravss, Bibliopolae Vindobonensis, Wien, Erzherzogtum Österreich (in Latin).
Sidjimova, B. 2006. Morphometrical variability in Bulgarian Galanthus elwesii (Amaryllidaceae). Proc. Balkan Bot. Congr. 28:205-210.

Sneath, P.H.A. and R.R. Sokal. 1973. Numerical taxonomy. W.H. Freeman, San Francisco, CA

Stern, F.C. 1956. Snowdrops and snowflakes. Roy. Hort. Soc., London, UK.

Stjepanović-Veseličić, L. 1975. Fam. Amaryllidaceae: Galanthus L., p. 596-605. In: M. Josifović (ed.). Flora SR Srbije. Vol. VII. Srpska Akademija Nauka i Umetnosti, Beograd, Srbija (in Serbian).

Tan, K., B. Biel, and S. Siljak-Yakovlev. 2014. Galanthus samothracicus (Amaryllidaceae) from the island of Samothraki, northeastern Greece. Phytol. Balcanica 20:65-70.

Thiers, B. 2018. Index herbariorum: A global directory of public herbaria and associated staff. New York Botanical Garden's Virtual Herbarium. 14 Feb. 2018. <http://sweetgum. nybg.org/science/ih/>.

Van Ooststroom, S.J. and Th.J. Reichgelt. 1964 Amaryllidaceae: Galanthus, p. 148-149. In: S.J. Van Ooststroom, Th.J. Reichgelt, R Van der Veen, S.E. De Jongh, E.A. Stafleu, and V. Westhoff (eds.). Flora Neerlandica. Vol. I (6). Koninklijke Nederlandse Botanische Vereniging, Amsterdam, The Nederland (in Dutch).

Webb, D.A. 1980. Galanthus, p. 77-78. In: T.G. Tutin, V.H. Heywood, N.A. Burges, D.M. Moore, D.H. Valentine, S.M. Walters, and D.A. Webb (eds). Flora Europaea. Vol. V. Cambridge Univ. Press, Cambridge, UK.

Wulfen, F.X. 1858. Flora Norica phanerogama. C. Gerold's Sohn, Wien, Kaiserthum Oesterreich (in German).

Zahariadi, C. 1966. Fam. Amaryllidaceae Jaume St. Hil, p. 404-435. In: E.I. Nyárády (ed.). Flora Republicii Socialiste România. Vol. XI. Editura Academiei Republicii Socialiste România, Bucureşti, România (in Romanian).

Zeybek, N. and E. Sauer. 1995. Türkiye Kardelenleri (Galanthus L.). Vol. I. Ege Üniversitesi Basimevi, İzmir, Türkiye (in Turkish).

Zonneveld, B.J., J.M. Grimshaw, and A.P. Davis. 2003. The systematic value of nuclear DNA content in Galanthus. Plant Syst. Evol. 241:89102. 


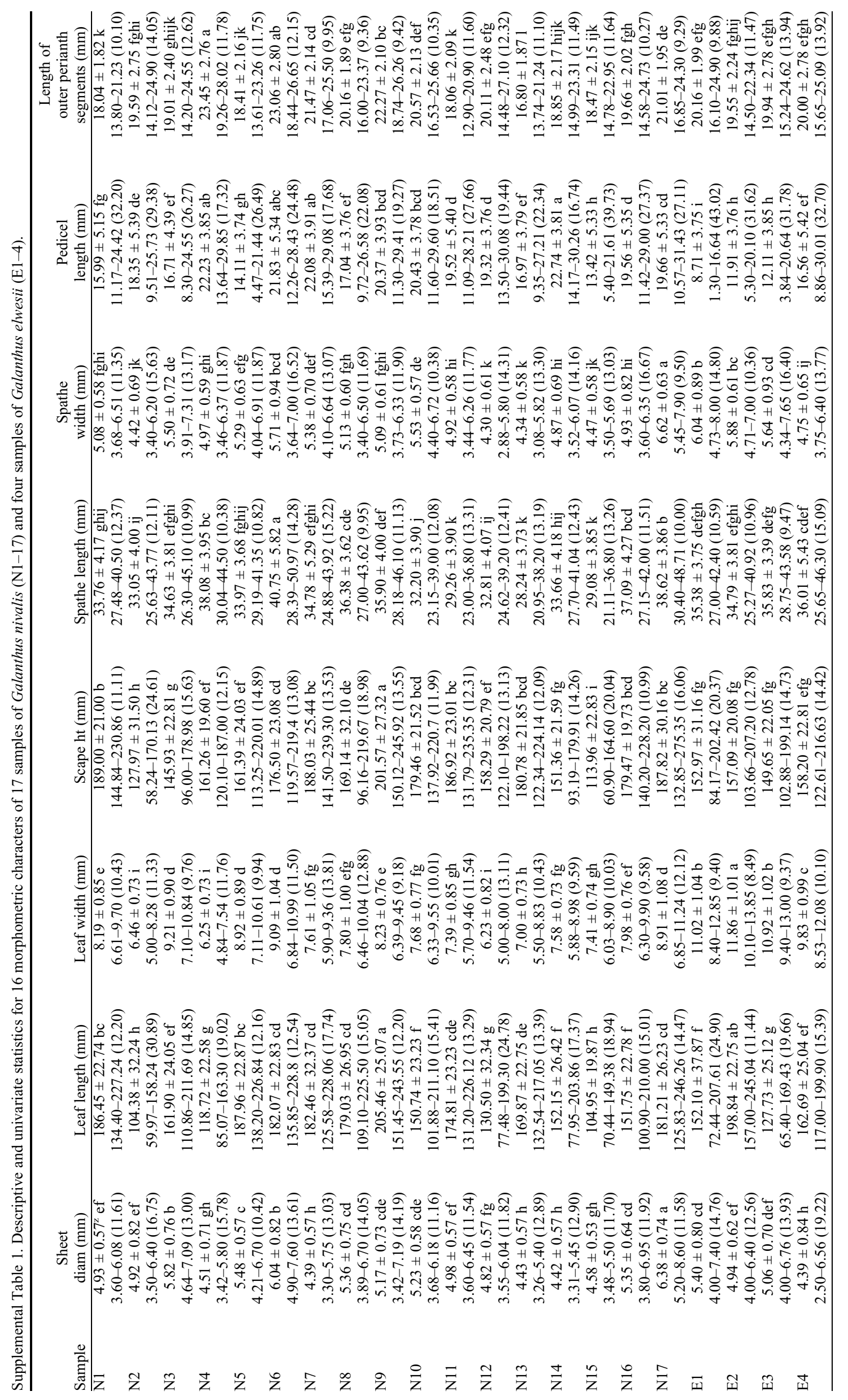

HortScience Vol. 53(8) August 2018 


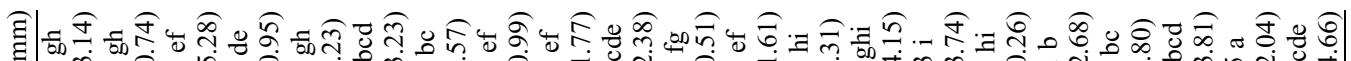

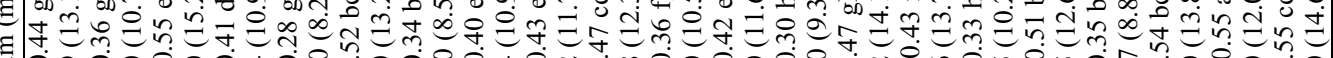

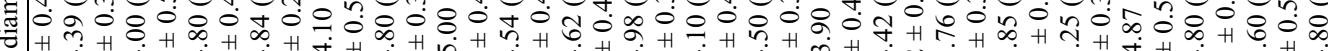

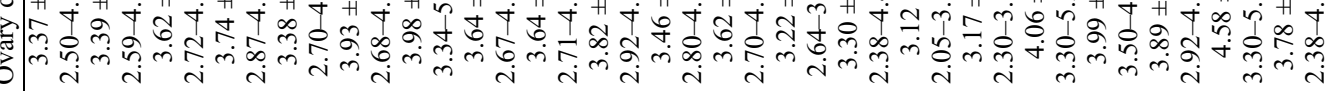

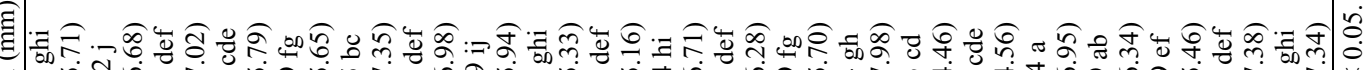

F పी

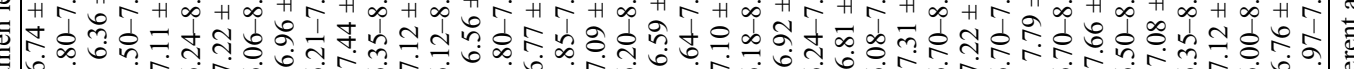

里

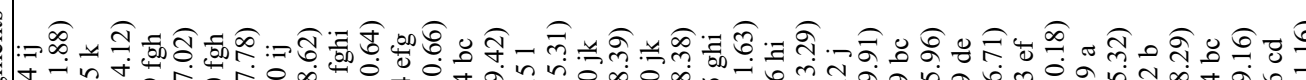

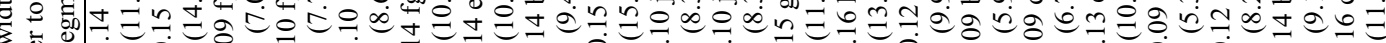
o

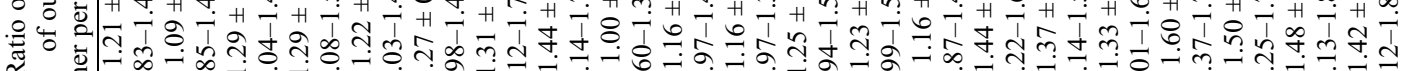

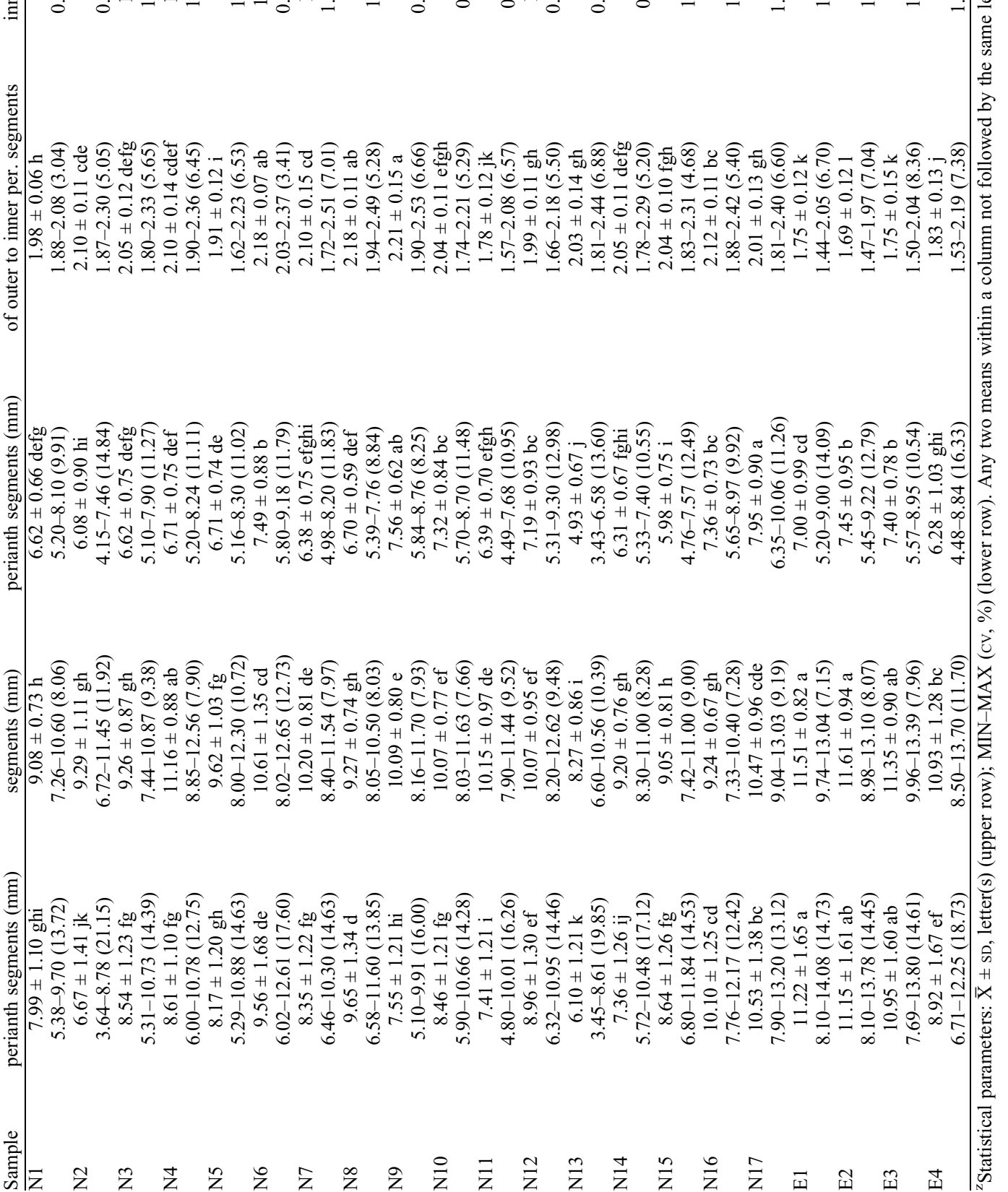




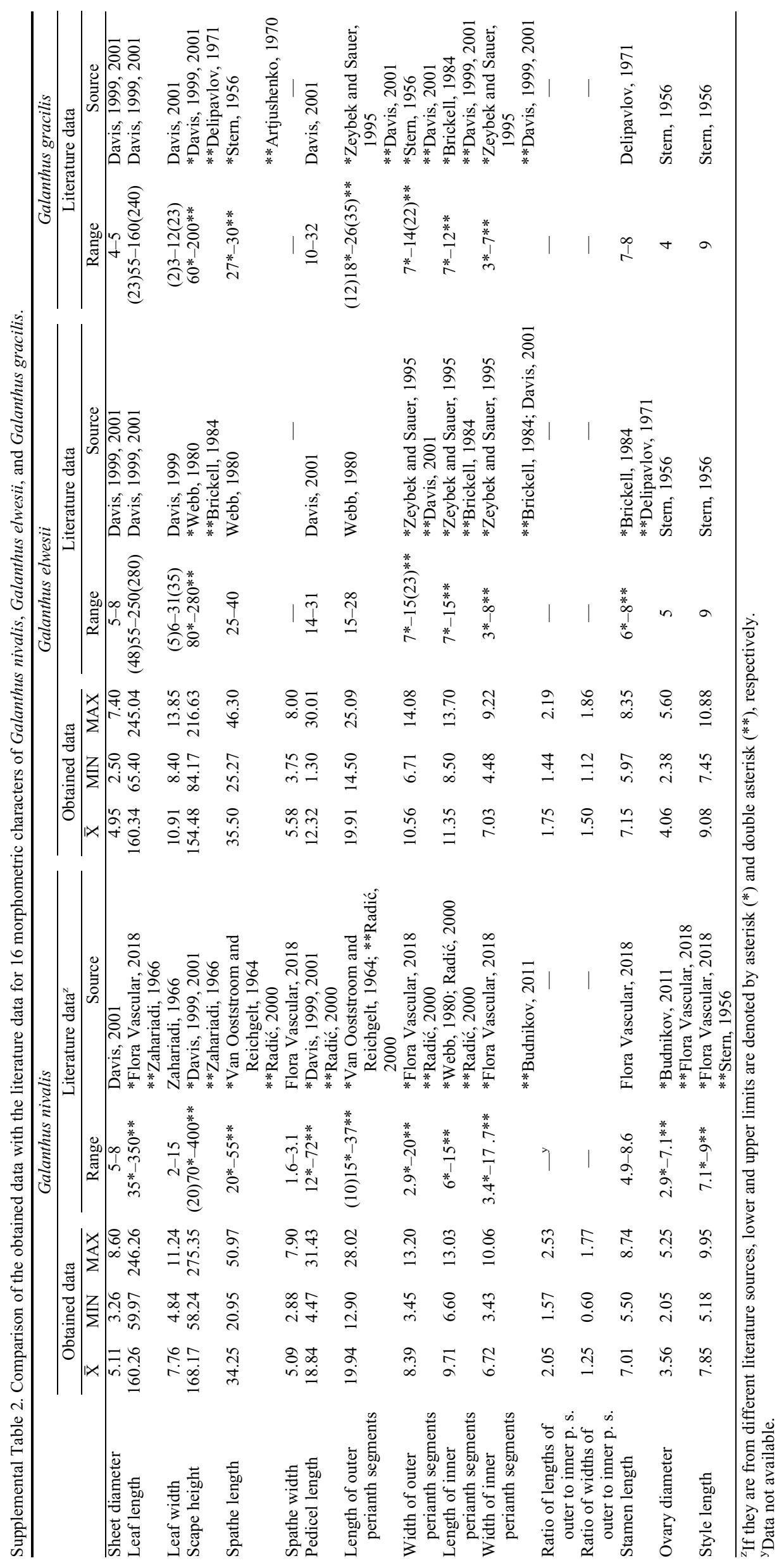




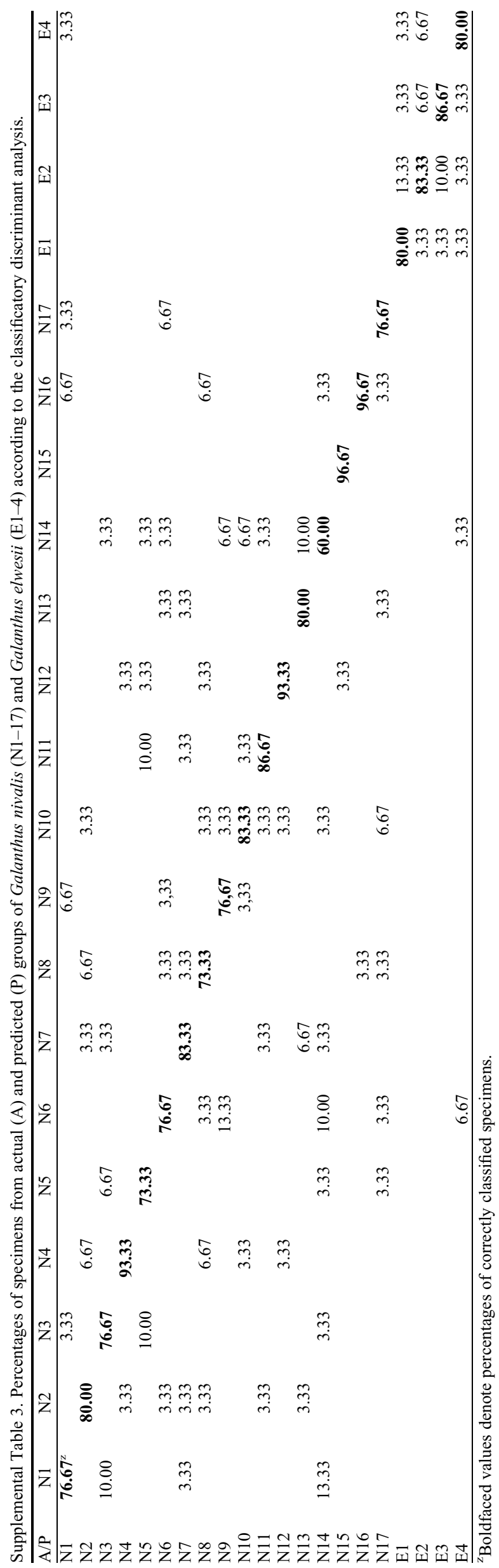

